\title{
AUTOMOTORES ORLETTI E A PERSEGUIÇÃO CONTRA OS URUGUAIOS NA ARGENTINA: DITADURAS DE SEGURANÇA NACIONAL, TERRORISMO DE ESTADO E CONEXÃO REPRESSIVA NO CONE SUL
}

\section{Introdução}

Enrique Padrós ${ }^{1}$

O Centro Clandestino de Detenção Automotores Orletti ocupou um espaço relevante dentro da dinâmica e como infraestrutura para a atuação da Operação Condor na Argentina, considerando que foi o local destinado a receber os cidadãos uruguaios, chilenos e paraguaios caçados e sequestrados pelos Grupos de Tarefas locais, que agiam em conjunto com unidades operativas das ditaduras vizinhas, após o golpe de Estado de 1976. O foco da análise está centrado no caso particular dos perseguidos políticos uruguaios do Partido por la Victoria del Pueblo (PVP). ${ }^{2}$ A presença destes exilados em território argentino ocorre em um contexto de fechamento regional dos espaços democráticos e de advento e consolidação de um verdadeiro cinturão de Ditaduras de Segurança Nacional no Cone Sul. A caracterização do regime repressivo que viabiliza a perseguição desses exilados - através da coordenação repressiva entre as ditaduras uruguaia e argentina -, contribui na compreensão do funcionamento de Orletti, da linha de comando envolvida, dos vínculos dentro da estrutura repressiva maior e do perfil das vítimas bem como seu destino.

$\mathrm{O}$ arcabouço teórico do artigo se sustenta na perspectiva de que os regimes de exceção do Cone Sul, dos anos 1960 a 80, constituíram-se enquanto Ditaduras de Segurança Nacional (DSN) que utilizaram mecanismos de Terrorismo de Estado (TDE) para a sua imposição e consolidação e se integraram através de vínculos repressivos extraterritoriais como no caso da Operação Condor. A base documental utilizada se compõe de: a) documentos produzidos pelos órgãos de segurança; b) denúncias e informes apresentados por organizações de direitos humanos; c) material de imprensa; d) bibliografia especializada no tema central e nos seus derivados (parte dela produzida por pesquisadores que também são sobreviventes dos acontecimentos registrados). $\mathrm{O}$ fato de a coordenação repressiva ser uma dinâmica marcadamente encoberta pelas Forças Armadas da região, inclusive até os dias de hoje, obriga a potencializar as informações existentes, quase sempre muito fragmentadas, mas necessárias na tentativa de preenchimento das lacunas deixadas no rastro dos crimes realizados além das fronteiras nacionais. Destarte, as ações de checagem, cruzamento e contraste crítico das fontes existentes, mesmo que produzidas segundo lógicas diferentes, tem sido vital para o esclarecimento de muitas questões que dizem respeito a essa dinâmica repressiva.

\footnotetext{
1 Professor do Departamento de História e do Programa de Pós-Graduação em História/UFRGS. e-mail: lola@adufrgs.ufrgs.br.

${ }^{2}$ O Partido por la Victoria del Pueblo (PVP) foi fundado em Buenos Aires, em 1975. Surgiu como síntese entre correntes de origem e tradição anarquista, marxista e socialista, cujos militantes decidiram integrar-se em uma nova estrutura política que pudesse ser mais eficiente para enfrentar o difícil contexto de um país tomado por uma brutal ditadura e um exílio pressionado pela coordenação repressiva regional. Após ter sofrido violenta perseguição e ser alvo do extenso braço extrafronteiriço da repressão uruguaia, com o fim da ditadura, se inseriu na vida política do país, como uma das forças da coalizão de esquerda Frente Ampla. Desde então, ocupa um espaço político relativamente pequeno em termos eleitorais, mas com representação parlamentar e com forte ativismo na área dos direitos humanos e do sindicalismo. 


\section{Ditaduras, repressão encoberta e desaparecimentos}

A análise da problemática proposta relaciona-se, em primeiro lugar, com o conceito de Ditaduras de Segurança Nacional. Parte-se da perspectiva de que tais regimes também foram ditaduras de classe; nesse sentido, mesmo reconhecendo certa autonomia militar - variável em cada caso nacional e em determinados momentos conjunturais -, considera-se que essa autonomia, de maneira geral, não se sobrepõe ao domínio e interesses da grande burguesia e do grande capital. Entre os aspectos constitutivos comuns às mesmas destacam-se uma base doutrinária principal (a DSN), o alinhamento político, militar e econômico aos Estados Unidos da América - sobretudo quanto à imposição de dispositivos de contenção do comunismo e defesa dos cânones do capitalismo e da sua reestruturação segundo as necessidades do pós-guerra -, bem como uma concepção de guerra contra-insurgente ilimitada contra todo questionamento às estruturas de dominação. Diante de tais problemáticas há coincidência com as análises seminais de Josep Comblin, Baumgartner \& Duran e Tapia Valdéz. ${ }^{3}$

Além de características próximas ou assemelhadas, essas ditaduras tiveram diversos elementos concretos de conexão, entre os quais a prática repressiva contra os setores e indivíduos percebidos como inimigos comuns (ou seja, todos aqueles identificados como "inimigos internos" por cada uma das ditaduras). A violência estatal contra esses opositores, tanto dentro como fora do território nacional, implicou na montagem de importante infraestrutura que permitisse, inclusive, negar sua própria existência. A categoria Terrorismo de Estado expressa tal realidade:

(...) un modelo estatal contemporáneo que se ve obligado a transgredir los marcos ideológicos y políticos de la represión 'legal' (la consentida por el marco jurídico tradicional) y debe apelar a 'métodos no convencionales', a la vez extensivos $e$ intensivos, para aniquilar a la oposición política y la protesta social, sea armada o desarmada. ${ }^{4}$

De forma explícita, a violência estatal, traduzida em sequestros, tortura massiva, execuções extrajudiciais e desaparecimento de pessoas e cadáveres, é o braço executor da burocracia estatal civil e militar, o que permite que toda a estrutura pública, em caso de necessidade, seja colocada à disposição da luta contra o inimigo interno. ${ }^{5}$ Um dos fatores fundamentais para ter sucesso na grande tarefa de "limpeza política" regional foi o uso de comandos clandestinos que funcionavam como parte do Estado paralelo característico do $\mathrm{TDE}^{6}$. Tal infraestrutura era fundamental e se justificava a partir de uma premissa essencial daquelas ditaduras: esconder e manipular toda evidência que pudesse denunciar a brutalidade de uma ação punitiva sem precedentes. ${ }^{7}$

A DSN tinha como foco angular a perspectiva da Guerra Fria; dentro dessa lógica, a propaganda disseminada pelo Pentágono e amplificada pelos meios de comunicação continentais afins, apresentava a União Soviética e o comunismo internacional como uma ameaça letal para os valores e a estabilidade das sociedades americanas. Em síntese, se a subversão era fomentada cabia uma reação contundente. Frente a isso, a superpotência capitalista, auto proclamada defensora do "mundo livre" $e$ da democracia, impôs uma aliança militar que se sobrepôs aos interesses econômicos anteriormente

\footnotetext{
${ }^{3}$ Respectivamente: COMBLIN, Josep. A Ideologia da Segurança Nacional. O Poder Militar na América Latina. Rio de Janeiro: Civilização Brasileira, 1978; BAUMGARTNER, José Luis \& DURAN MATOS, Jorge. América Latina: liberación nacional. Montevideo: Banda Oriental, 1985, 2 Vol.; TAPIA VALDÉS, Jorge A. El Terrorismo de Estado. La Doctrina de Seguridad Nacional en el Cono Sur. México: Nueva Imagen, 1980.

${ }^{4}$ BONASSO, Miguel. Prefacio. In: PIETERSEN, Jan et al. Terrorismo de Estado. El papel internacional de EE.UU. Navarra: Txalaparta, 1990, p. 9.

${ }^{5}$ BAYER, Osvaldo y otros. El terrorismo de estado en la Argentina: apuntes sobre su historia y sus consecuencias. Buenos Aires: Instituto Espacio para la Memoria, 2010, p. 19.

${ }^{6}$ MIGNONE, Emilio F. \& CONTE Mc DONNELL, Augusto. Estrategia represiva de la dictadura militar: la doctrina del paralelismo global. Buenos Aires: Colihue, 2006.

${ }^{7}$ Havia demanda de armas, munições, veículos, equipamento de comunicações, locais encobertos (de triagem, detenção e isolamento), serviços de documentação, material humano (unidades de reclusão e pessoal de saúde), cobertura institucional, etc. AMNISTÍA INTERNACIONAL. Desapariciones forzadas y homicidios políticos. La crisis de los derechos humanos en los noventa. Manual para la acción. Madrid: Editorial Amnistía Internacional (EDAI), 1994, p. 95. 
estabelecidos, redimensionando as ligações com os setores dominantes locais de perfil conservador ou liberal. A DSN funcionou muito mais como uma construção ideológica do que como um instrumento doutrinário funcional, como apontou o estudo clássico do já citado Comblin ${ }^{8} e$ corroborou, posteriormente, Nilson Borges. ${ }^{9}$

Por outro lado, a evolução do equilíbrio de forças nas relações internacionais, particularmente entre as superpotências, extremou os cuidados e exigências dos EUA na região. A Revolução Cubana foi fator emblemático nesse contexto; contudo, se bem seja verdade que com ela a Guerra Fria se tornou explícita no continente, desde muito antes, o Pentágono vinha promovendo intervenções e rupturas antidemocráticas e antipopulares na América Latina, como mostram os dramáticos e violentos acontecimentos que se sucederam na primeira metade dos anos 50. Já, nos anos 60 , a fermentação revolucionária e a exponencial desigualdade social que se praticava na região levaram a uma realidade corroída de tensões. A visualização de setores e sentimentos anti-imperialistas que visavam desestabilizar as relações dos seus governos com os EUA, ratificou a necessidade da eliminação daqueles por constituírem focos de tensão. Mais do que nunca, a política externa da superpotência definiu que a defesa dos seus interesses na América Latina - sua zona de influência abalada desde 1959 - exigia assumir que os mercados da região eram essenciais para os seus interesses; quer dizer, reafirmava a percepção de que o subcontinente era uma espécie de extensão da sua área de dominação e controle econômico - em outras palavras, extensão do seu mercado interno. Sendo assim, os assuntos de segurança interna desses países foram compreendidos como próprios e os inimigos internos de cada formação social passaram a ser vistos como próprios.

A DSN, produzida nos EUA, reinterpretada e ampliada na região, defendia a atuação política das Forças Armadas; segundo ela, a contaminação do mundo da política pela infiltração de ideias $e$ agentes externos tornava necessário um processo radical de descontaminação, o que somente poderia ser levado a cabo pelas forças de segurança, únicas entidades nacionais imunes à conquista dos "corações e mentes' promovida pelo comunismo internacional. Portanto, os militares, em nome da defesa dos valores sagrados da sociedade ocidental deviam assumir o poder político e reestruturá-lo, o que significava uma novidade em relação ao uso recorrente que as classes dominantes tinham feito dessas forças até então, ou seja, derrubar governos hostis e efetuar uma rápida "limpeza" políticoadministrativa antes da devolução do poder aos setores civis confiáveis. No marco da DSN a subordinação do poder civil era uma das consequências diretas da nova postura da corporação militar; ordem e estabilidade foi o horizonte primeiro dos objetivos dos regimes de exceção. Na medida em que o conflito social devia ser evitado, toda protesta foi virulentamente proibida e combatida. $\mathrm{O}$ Estado virou instrumento de irradiação de valores castrenses (disciplina, verticalidade, hierarquia $e$ obediência) sobre o conjunto da sociedade. O resultado desta orientação significou a extrapolação ilimitada da ação militar; as Forças Armadas se perceberam como fator fundamental da "construção nacional", com a decorrente tendência de intervir em todos os âmbitos da sociedade e de impor sua obsessão pelo tema da segurança. Nesse sentido, a aplicação da DSN aproximou as práticas de violência preventiva e de violência repressiva, rejeitando os limites da tradição constitucional $e$ democrática. A ação punitiva objetivou a suspeição, mesmo antes do pronunciamento judicial (ou com a sua omissão ou colaboração). Paradoxalmente, a imposição da segurança a qualquer custo acentuou o clima de insegurança ancorado na ostentação de impunidade e na ausência de controle e fiscalização por parte dos demais poderes, na aplicação de uma coerção estatal ilimitada. ${ }^{10}$

Outro objetivo dessas ditaduras foi, além do anticomunismo militante, a identificação, anulação ou eliminação dos denominados inimigos internos vistos como "subversivos", "contaminados" por ideias e influências "estranhas"; na prática, tal enquadramento abrangeu qualquer manifestação de descontentamento diante da ordem vigente. A elasticidade funcional do anticomunismo tornou o inimigo interno uma identidade abstrata definida pelo sistema com um perfil muito variado e difuso;

\footnotetext{
${ }^{8}$ COMBLIN, "A ideologia...".

${ }^{9}$ BORGES, Nilson. A Doutrina de Segurança Nacional e os governos militares. In FERREIRA, Jorge \& DELGADO, Lucília de A. N. (Org.). O tempo da ditadura: regime militar e movimentos sociais em fins do século XX. Rio de Janeiro: Civilização Brasileira, 2003.

${ }^{10}$ PADRÓS, Enrique Serra. A ditadura civil-militar uruguaia: doutrina e segurança nacional. Varia História, Belo Horizonte, vol. 28, n 48, jul/dez 2012, p. 515.
} 
inicialmente, ficou quase restrito aos militantes de organizações armadas e lideranças mais notórias de esquerda e centro-esquerda reconhecidas como nocivas para o status quo vigente em cada país. Esses inimigos internos acabaram associados à ideia de subversão, sedição ou terrorismo, segundo o léxico predominante em cada ditadura. Com o passar do tempo, diante da vontade de permanência no poder dos setores golpistas foi necessário ampliar o universo de potenciais ameaças letais, como forma de legitimar o continuísmo na ocupação do Estado. Consequentemente, de forma similar ao que fora feito com o comunismo, a constante flexibilização do conceito de inimigo, incorporando novos alvos políticos funcionou como fator de legitimação permanente do sistema e do TDE e aumentou, acentuadamente, o espectro dos suspeitos de tentar agredir a nação e o "mundo livre".

O envolvimento das Forças Armadas na dinâmica persecutória foi crucial. Embora o Exército fosse o setor de maior participação, as demais armas e unidades policiais participaram ativamente da grande caçada. O fundamental era garantir que, tanto no controle geral da perseguição quanto no funcionamento das diversas unidades que participavam do mesmo, existisse comando centralizado, agilidade operacional, abrangência nacional, treinamento e armamento específico, disciplina, hierarquia e obediência. Na essência intrínseca dessa atuação houve especial destaque para os serviços de informação, normalmente vinculados às tarefas de mapeamento da oposição e dos suspeitos bem como de fornecimento de informação aos Grupos de Tarefas e demais unidades de operações (aquelas diretamente envolvidas no enfrentamento militar da "subversão").

A maquinaria da violência estatal se alimentava do ciclo monitoramento, sequestro, tortura, execução extrajudicial e desaparecimento do cadáver. ${ }^{11}$ De forma geral, essa sistemática de atuação ocorreu em todo o Cone Sul, embora com intensidade e matizes variados. A política de sequestros semeava, no entorno da vítima, a incerteza e o total desconhecimento do ocorrido. Assim, a pessoa sequestrada pelo próprio Estado - fato devidamente negado por ele -, ficava totalmente a mercê dos captores. Os familiares, companheiros, colegas ou advogados que tentavam intervir uma vez constatada a ausência, não tinham informação precisa nem sabiam por onde começar a procurar, situação que piorava ainda mais quando se tratava de opositores que viviam na clandestinidade. $\mathrm{O}$ desaparecimento dos corpos dos sequestrados, executados ou mortos na tortura, era o corolário $e$ refinamento maior da lógica do TDE: não havendo corpo, não havia vítima; não havendo vítima, não havia crime. Sem corpo e sem vítima se escondia com bastante eficiência o resultado dos "interrogatórios" - da tortura - $e$ as marcas da execução. ${ }^{12}$

A aplicação das diretrizes da DSN se coadunou com a existência do Terrorismo de Estado. Dentro da compreensão da guerra contrainsurgente, uma variada gama de mecanismos administrativos, propagandísticos, psicológicos e jurídicos deram suporte às atividades, clandestinas ou não, das unidades estatais de inteligência, informação e controle. Nenhum setor da sociedade ficou incólume ao TDE, o qual foi aplicado desde o centro do poder, dentro ou fora das fronteiras nacionais e que recorreu a métodos não convencionais para eliminar a oposição política e o protesto social. ${ }^{13} \mathrm{~A}$ criação de uma estrutura estatal clandestina, paralela à estrutura legal e visível do Estado neutralizou o clamor interno e reforçou ações que produziram diversos efeitos psicológicos. A percepção de uma repressão anônima, clandestina e onipresente gerou nos atingidos, uma sensação devastadora de abandono diante da perda de solidariedade e reforçou a atmosfera de medo, o que levou a população a uma postura de quase inércia, reduzindo sensivelmente a luta por direitos políticos e reivindicações socioeconômicas. Em sintonia com Juan Corradini entende-se que

\footnotetext{
${ }^{11}$ Como aponta Alejandra Pascual a estratégia do desaparecimento como política repressiva implicou as seguintes etapas: a) seqüestro da vítima; b) transferência a um centro clandestino de detenção; c) prisão ilegal; d) submissão a torturas; e) eliminação ou, em certos casos, "legalização" da situação de detenção da vítima. PASCUAL, Alejandra L. Terrorismo de Estado. A Argentina de 1976 a 1983. Brasília: Editora Universidade de Brasília, 2004, p. 62.

${ }^{12}$ Nos casos onde a prática do desaparecimento foi aplicada em escala significativa encontram-se certas justificativas comuns, entre elas: obtenção de enormes vantagens sobre o inimigo; aplicação de pena de morte sem base jurídica; proteção da estrutura repressiva dos seus erros e "excessos"; evitar represálias; e diluição de responsabilidades futuras.

${ }^{13}$ BONASSO, "Prefacio...", p. 9. 
El terror tiene como objetivo no solo controlar, sino también cambiar a los actores sociales. Es esencialmente una técnica de desorientación, que apunta a privar a los sujetos de la oportunidad de calcular y prever las consecuencias de sus acciones. Es una forma de poder en la cual la conformidad no garantiza la seguridad. Su efecto principal es la generación de una atmósfera de ansiedad - una 'cultura de miedo'. ${ }^{14}$

A "cultura do medo" anestesiou a capacidade de resistência e articulação das sociedades sob o crivo da DSN e do TDE. A sistemática repressiva resultante fomentou uma onda de "violência irradiada" ${ }^{15}$ que se disseminou como espiral crescente a partir dos círculos concêntricos do entorno mais imediato de cada perseguido (a família, os amigos, o bairro, os locais de estudo e de trabalho, etc.); as pessoas que orbitavam nesses círculos, se tornavam, por sua vez, alvos potenciais de vigilância e suspeição e ao redor de cada uma delas, novos círculos concêntricos se conformavam. Desta forma, através da ameaça e do medo, a violência irradiada aguçou a solidão $e$ o isolamento do perseguido. E quanto mais distantes os bordes externos do centro de cada um dos círculos concêntricos monitorados $e$ vigiados, mais efetiva acabou sendo a disseminação dos efeitos perversos do TDE, quantificando ainda mais a "rentabilidade do terror" promovido. ${ }^{16}$

Findo o ciclo dessas ditaduras, fatos denunciados durante a vigência das mesmas foram confirmados pelos testemunhos colhidos por comissões da verdade e divulgados em relatórios nacionais produzidos dentro do espírito do "Nunca Mais". Em função disso, os desaparecimentos passaram a ser vistos como crimes deliberados, "perpetrados por orden de un gobierno o con su complicidad o consentimiento." ${ }^{17}$

A relação entre os serviços de inteligência e os grupos operativos foi marcada pela fluidez da informação, destacando-se a centralização do sistema desde o comando militar, em ordem decrescente e hierárquica. Deve salientar-se, porém, que essa hierarquia de comando, particularmente em relação às unidades acobertadas dentro do esquema da coordenação regional, não era, necessariamente, a mesma que a da lógica militar. Quanto a isso, não foi incomum encontrar, em unidades que agiram nessa esfera, situações nas quais oficiais inferiores, que delas faziam parte, tinham maior poder que outros de maior graduação, mas que não estavam tão envolvidos nessas atividades.

Quanto à metodologia repressiva, a partir do binômio sequestro-detenção, ocorria o traslado para um local e um destino incerto. No caso da Argentina, a grande maioria das vítimas foi distribuída dentro de uma rede de centenas de centros clandestinos, vários deles no interior de estabelecimentos militares legais, como a Escola de Mecânica da Armada (ESMA). Parte dessas unidades de reclusão se especializou em funções de triagem, passagem, interrogatório (tortura) ou, então, em determinadas organizações de oposição. Isto valia, também, para o número impreciso, mas significativo, de cidadãos exilados na Argentina no momento do golpe de Estado de 1976, particularmente paraguaios, chilenos e uruguaios. Dentro desse quadro, Automotores Orletti foi o espaço operativo mais importante das unidades de segurança focadas na comunidade de exilados. No caso dos comandos uruguaios, Orletti foi, sem dúvida, a base de maior volume de atuação.

No que diz respeito às vítimas, a partir do momento do sequestro, iniciava-se um duro suplício, pois perdiam seus direitos básicos, eram privadas de qualquer comunicação com o mundo exterior $e$ terminavam confinadas em locais desconhecidos num clima de total incerteza quanto à expectativa do destino imediato. $\mathrm{O}$ estudo sobre o alcance da repressão argentina implica em reconhecer um fator inédito: o sequestro de centenas de crianças filhas de perseguidos políticos. A organização Abuelas de Plaza de Mayo denuncia que ao redor de 500 crianças foram sequestradas ou nasceram em cativeiro. A mesma organização há muito tempo, associa tais sequestros a uma política deliberada de "roubo de

\footnotetext{
${ }^{14}$ CORRADI, Juan. El método de destrucción. El Terror en la Argentina. In: QUIROGA, Hugo; TEACH, César (Comps). A veinte años del golpe. Con memoria democrática. Rosario: Homo Sapiens Ediciones, 1996. p. 89.

${ }^{15}$ ABOS, Álvaro. La racionalidad del Terror. El Viejo Topo, Barcelona, n. 39, dic. 1979.

${ }^{16}$ PADRÓS, Elementos constitutivos do Terror de estado implementado pelas Ditaduras Civis-Militares de Segurança Nacional latino-americanas. In: PADRÓS, Enrique Serra (Org.). As Ditaduras de Segurança Nacional: Brasil e Cone Sul. Porto Alegre: CORAG, 2006. p. 17.

${ }^{17}$ Trata-se de execuções extrajudiciais, não acidentes, recorrentes de excessos ou obra de soldados ou policiais que agiram isoladamente, fatos previstos ou absorvidos dentro de uma rede de comando cujas decisões e ordens emanaram de esferas governamentais. AMNISTÍA INTERNACIONAL, "Desapariciones forzadas...", p. 93.
} 
bebês", como parte do "botim de guerra" ${ }^{18}$, noção que advém do entendimento de que as crianças sequestradas, talvez em função do meio social de origem, eram valorizadas por serem intelectualmente muito espertas e fisicamente saudáveis. ${ }^{19}$ Mais de duas dezenas de crianças filhas de cidadãos uruguaios desapareceram na Argentina; algumas nasceram em cativeiro. Várias foram entregues à família dias ou semanas após o sequestro. Em Orletti há registros de sobreviventes que reconhecem a presença de crianças $e$, entre elas, há casos que viraram emblemáticos e foram diretamente relacionados à conexão repressiva regional ${ }^{20}$; quase todas acabaram seqüestradas e desaparecidas em ações que visavam seus pais e nas quais participaram agentes da ditadura uruguaia.

\section{Uruguaios na Argentina: o que faziam lá?}

Após o golpe de Estado uruguaio, em junho de 1973, milhares de cidadãos se deslocaram à Argentina, muitos à procura do estatuto de asilado ou refugiado; outros, entre tantos exilados, realizavam um recuo tático sob orientação de suas organizações, à espera da melhoria nas condições de atuação (caso de integrantes da guerrilha tupamara); havia, todavia, um contingente numeroso que vivia totalmente legalizado, constituindo uma comunidade com identidade própria e ocupando abertamente espaços profissionais e de estudo. Nesse momento, a Argentina vivia uma experiência a contrapelo do resto do Cone Sul; com a volta de Perón à presidência da república, em 1973, o país retomava uma vida democrática interrompida quase uma década antes; apesar da instabilidade existente, o cenário era atrativo para quem vivia sob ameaça iminente de prisão ou risco de vida nos países vizinhos. Cabe lembrar que o Brasil e o Paraguai sofriam ditaduras há mais tempo e que o Chile sofreria brutal retrocesso constitucional em setembro de $1973 \mathrm{com}$ a queda do governo da Unidade Popular e a ascensão de Augusto Pinochet. Aliás, a queda de Salvador Allende e seu governo socialista implicaram em dramática tentativa de fuga de milhares de exilados de todo o continente que tinham escolhido o país transandino como local de refúgio, mas, também, de colaboração na construção de um socialismo sob parâmetros democrático burgueses. Esses esquerdistas latino-americanos, alvo de perseguição nos seus países de origem constituíram um grupo especialmente visado pelos golpistas chilenos, inviabilizando sua permanência no país; se detidos, seu destino seria a prisão, a execução ou a entrega às ditaduras das quais tinham fugido. Portanto, o desespero tomou conta da diáspora latinoamericana no 11 de setembro de 1973. Com o estrangulamento coercitivo promovido nos aeroportos, sobrou como meio de fuga atravessar, baixo duríssimas condições, a cordilheira andina, em direção à Argentina, ou, então, procurar acolhida em embaixadas solidárias (ou pelo menos pouco hostis), que rapidamente colapsaram diante da explosão da tragédia humanitária. Em contrapartida, as embaixadas das ditaduras do Cone Sul bloquearam seu acesso e lacraram seus portões, inclusive aos seus compatriotas, insensíveis ao drama que transcorria fora das grades e muros. Assim, a partir desse momento, no Cone Sul só restava a Argentina - principalmente Buenos Aires -, como possibilidade de santuário ou terra de acolhida para milhares de perseguidos políticos latino-americanos $e$, especialmente, uruguaios.

O conjunto de exilados orientais aproveitou a curta e tênue primavera democrática argentina para multiplicar contatos políticos e desenvolver campanha de denúncia contra as arbitrariedades cometidas em seu país. Em função disso, a ditadura comandada pelo presidente golpista Juan María Bordaberry intensificou a realização de operações de vigilância ou de ameaça ostensiva contra aqueles que, fugindo, se haviam estabelecido do outro lado do Río de la Plata. Simultaneamente, mesmo antes do golpe da Junta Militar, no frenesi dos últimos dias do conturbado governo de Isabel Perón, os esquadrões paramilitares da Aliança Anticomunista Argentina (Triple A) semeavam o pânico entre a

\footnotetext{
${ }^{18}$ NOSIGLIA, Julio E. Botin de guerra. Buenos Aires: Editorial de La Página, 1997.

${ }^{19}$ Trata-se de uma forte hipótese manejada pelas organizações de direitos humanos na tentativa de entender o critério dos agentes repressivos e o processo sequestro-adoção/apropriação de crianças por casais vinculados, majoritariamente, à repressão ou do seu entorno próximo. SERPAJ. Uruguay Nunca Más. Informe Sobre la Violación a los Derechos Humanos (1972-1985). Montevideo: SERPAJ, 1989, p. 295.

${ }^{20}$ ROCHA, Jan. Solidariedade não tem fronteiras: a história do grupo Clamor com os refugiados latino-americanos. São Paulo: Outras Expressões, 2018. OLIVERA, Raúl \& MÉNDEZ, Sara. Secuestro en la Embajada. El caso de la maestra Elena Quinteros. Caracas: El perro y la rana, 2009. p. 85 e 86. 
esquerda argentina e o exílio latino-americano. ${ }^{21}$ Seus ataques contavam com a anuência do governo peronista. Aliás, antes de falecer em 1974, o mesmo Perón havia esclarecido ao subdiretor da CIA, general Vernon Walters, que os temores de Washington de uma radicalização à esquerda do seu governo não tinham o menor fundamento; pelo contrário, manifestava estar empenhado na contenção dos grupos radicais. ${ }^{22}$

Com a instalação da Junta Militar presidida pelo general Jorge Rafael Videla a percepção que os exilados tiveram da nova situação foi a de sentir-se encerrados em uma terrível armadilha, cercados por todos os lados. Efetivamente, à diferença do ocorrido nos países vizinhos - onde foi estimulada a saída dos principais quadros organizativos da oposição -, na Argentina, a situação foi diferente. $\mathrm{O}$ território nacional foi concebido como uma garrafa de gargalo muito estreito por onde milhares de pessoas procuravam passar. A ditadura aplicou uma espécie de torniquete sobre esse gargalo visando impedir a fuga da região dos contingentes exilados e dos nacionais identificados como inimigos internos. Porque ocorreu esta mudança dentro do padrão regional anterior? Porque, no momento do golpe contra Isabel Perón, se aferia o custo político da movimentação dos exilados dos países vizinhos, em especial dos chilenos, na denúncia dos crimes e da violação dos direitos humanos. Ou seja, o governo liderado por Videla optou por resolver no seu território o embate com a oposição e tentar impedir uma atuação articulada de exilados como grupo de pressão municiando com denúncias à imprensa, à opinião pública internacional, aos partidos políticos e às instituições religiosas de posições próximas, visando enfraquecer a imagem da ditadura no exterior ${ }^{23}$. Assim, se desenvolveu um forte esquema de controle de fronteiras visando dificultar ao extremo o trânsito dos perseguidos políticos nacionais ou estrangeiros (Operativo Cerrojo - "Ferrolho"). ${ }^{24}$ Dependendo do contexto na própria cronologia da ditadura, a ênfase maior poderia estar colocada na saída de militantes ou na volta de quadros reagrupados e rearticulados no exterior (caso da Contraofensiva Montonera, no final dos anos 70). Esse forte controle de fronteiras se alimentava de instrumentos como as listas de procurados elaboradas pelos serviços de inteligência e a utilização de "marcadores", militantes presos levados aos passos de fronteira para identificar companheiros de organização cuja provável passagem tivesse sido detectada pelos serviços de inteligência.

A eficiência desse controle resultou, em realidade, da estrita vigilância sobre os pontos de acesso ou saída do país. Outro motivo que ajudou a entender a capacidade de atuação das Forças Armadas se concentra na postura militante da resistência no intuito de insistir em permanecer em território nacional apesar dos sinais evidentes de piora das condições de embate, postura que tinha antecedentes dramáticos na opção do MIR chileno de continuar no país após o golpe de Pinochet. Na Argentina, o PVP uruguaio teve um comportamento semelhante; o custo político da avaliação conjuntural foi terrível em termos de perdas humanas. A pergunta que se coloca é: porque a organização não deu ordem de retirada organizada dos seus quadros ante o advento da espiral repressiva, visível desde a atuação da Triple A? Vários são os fatores que devem ser levados em conta ao examinar o colapso das organizações armadas argentinas e da comunidade exilada no país. Em primeiro lugar, a presença de

\footnotetext{
${ }^{21}$ De 1974 até o golpe de Estado de 1976 foram assassinados onze cidadãos uruguaios na Argentina; outros cinco foram desaparecidos (inclusive uma criança). Alguns detidos foram entregues à ditadura uruguaia, como o caso de cinco militantes do Movimento de Libertação Nacional-Tupamaros, detidos e desaparecidos na Argentina, cujos cadáveres foram abandonados em lugar visível na pequena cidade de Soca, em uma comprovada ação de conexão repressiva.

${ }^{22}$ O Departamento de Estado diz que desde março de 1974: “(...) Perón autorizó a la Policía Federal Argentina y a los servicios de inteligencia argentinos a cooperar con la inteligencia chilena en la detención de los extremistas chilenos exiliados en la Argentina. Arreglos similares habían sido dispuestos con los servicios de seguridad de Bolivia, Uruguay y Brasil. Esta cooperación entre las fuerzas de seguridad aparentemente incluye la autorización para que funcionarios extranjeros operen dentro de la Argentina contra sus connacionales exiliados que utilizan ese país como base para operaciones de insurrección. Esta autoridad supuestamente incluye el arresto de tales exiliados y su traslado al país de origen sin recurrir a procedimientos legales". Documento desclasificado EUA [Resumen de la ley y práctica sobre terrorismo en la Argentina] citado por Martin Andersen no Dossier Secreto. El mito de la "guerra sucia" en la Argentina. Buenos Aires: Sudamericana, 2000, p. 135.

${ }^{23}$ PADRÓS, Enrique Serra \& SLATMAN, Melisa. "Brasil y Argentina: modelos económicos y redes de coordinación durante el último ciclo de dictaduras del Cono Sur. Estudio en clave comparativa y transnacional". IN: JENSEN, Silvina \& LASTRA, Soledad. (Editoras). Exilios: militancia y represión. Nuevas fuentes y nuevos abordajes de los destierros de la Argentina de los años setenta. La Plata: EDULP, 2014, p. 251-281.

${ }^{24}$ EJÉRCITO ARGENTINO. Plan del Ejército (Contribuyente al plan de seguridad nacional). Anexo 6, vigilancia de fronteras". Buenos Aires, febrero de 1976.
}

SÆCUlUM - Revista DE HistóRIa[39]; João Pessoa, jul./dez. 2018. 
uma ética militante de associar recuo com traição (traição aos ideais e aos companheiros caídos); em segundo lugar, a fidelidade voluntarista diante de um caminho percebido como sem retorno $e$ associado a um pacto de sangue com a memória dos companheiros mortos (como se houvesse uma dívida coletiva e individual com aqueles); em terceiro lugar, o reconhecimento de que o recuo era associado a claudicar, abandonar a luta, em suma, um ato de covardia; finalmente, a insistência em ficar no país como forma de evitar a solidão e o temor de que, no exílio, ocorresse a perda do pertencimento da identidade política. ${ }^{25}$

\section{A conexão repressiva, a Condor e Orletti}

O histórico de colaboração policial e militar na região é antigo. O quadro se intensificou no contexto da Guerra Fria, quando os EUA passaram a capacitar as forças de segurança da América Latina predicando a defesa hemisférica contra o comunismo. O grande símbolo da complexa infra-estrutura "pedagógica" espalhada através de cursos, manuais e missões militares foi a Escola das Américas, sediada na Zona do Canal do Panamá. Mediante a associação subordinada de interesses, os EUA assumiram o fornecimento de treinamento, logística, doutrinação e financiamento de apetrechos militares para a luta contrainsurgente. Indiretamente, incentivaram a integração das Forças Armadas regionais em volta dos valores ocidentais, do capitalismo e da DSN.

Independente de embates pontuais - geralmente relacionados com o grau de envolvimento dos EUA -, na historiografia sobre a Operação Condor existe certa coincidência quanto a um conjunto de aspectos basilares. ${ }^{26}$ Formalizada em 1975, foi o fruto do amadurecimento da posição de enfrentar duramente a radicalização dos setores populares, gerada por um aviltante processo de deterioração econômica e social regional. Em síntese, consistiu na extrapolação além-fronteiras dos mecanismos repressivos que vinham sendo utilizados no interior de cada ditadura, para neutralizar a atuação de resistência dos núcleos de exilados afixados na região. Sendo assim, através de intrincadas articulações estruturou-se uma rede de coordenação ultrassecreta das forças de segurança que, utilizando unidades especiais, procurou combater as denúncias orquestradas contra as ditaduras desde o exílio. No cerne do conveniado era vital a colaboração das autoridades locais, a permissão para infiltrar agentes nos territórios dos países associados com a devida garantia de imunidade para os mesmos, a troca permanente de informação, a realização conjunta de operativos, a detenção de opositores e a sua entrega aos países de origem.

Nos marcos dessa conexão repressiva regional foi de fundamental importância garantir impunidade e encobrimento das tarefas realizadas. A perseguição de inimigos internos que circulavam pela região (recuando, fugindo ou retornando), exigia coincidir no princípio das "fronteiras ideológicas". Segundo esta diretriz, a circulação ou presença desses militantes em qualquer país da região era um risco para todo o cinturão de ditaduras organizadas a partir das premissas da DSN. Portanto, era prioritário retirar as restrições para a circulação de comandos estrangeiros e garantir a colaboração das forças de segurança e inteligência locais. A persistência da "ameaça subversiva" tornou necessário delimitar "zonas libertadas" para a ação desses comandos fora das fronteiras nacionais, o que ampliou consideravelmente a capacidade estatal de monitoramento, contenção e execução, sem que isso ferisse outras soberanias territoriais.

O escritor uruguaio Fernando Butazzoni ${ }^{27}$, ao narrar um evento fictício emoldurado nos tempos da Condor como pano de fundo, alude à instigante existência de "janelas de segurança", dispositivos temporários de ausência de controle policial nos postos de fronteira de um determinado país, para facilitar a entrada e atuação de comandos estrangeiros no seu território onde, em tese, não tinham jurisdição para fazê-lo; ou seja, essas unidades externas recebiam o comunicado que anunciava liberdade de ação em um cenário "disponível" para execução de tarefas ilegais.

\footnotetext{
${ }^{25}$ TRİAS, Ivone \& RODRÍGUEZ, Universindo. Gerardo Gatti revolucionário. Montevideo: Trilce, 2012, p. 305.

${ }^{26}$ MCSHERRY, Patrice. Los Estados Depredadores: la Operación Cóndor y la guerra encubierta en América Latina. Montevideo: Banda Oriental, 2009. Também: CALLONI, Stella. Los años del lobo. Operación Cóndor. Buenos Aires: Peña Lillo/Continente, 1999; DINGES, John. Os anos do Condor: uma década de Terrorismo internacional no Cone Sul. São Paulo: Companhia das Letras, 2005.

${ }^{27}$ BUTAZZONI, Fernando. Las cenizas del cóndor. Montevideo: Planeta, 2014, p. 522. 
A cooperação entre sócios da conexão regional impunha códigos e regras que deviam ser respeitados. Os fluxos de informação estratégica precisavam ser alimentados e atualizados para evitar mal-entendidos, fricções ou falhas de comunicação entre as unidades envolvidas nas áreas onde as ações iriam ocorrer. Dentro da estrutura militar-policial das Ditaduras de Segurança Nacional, a informação sobre as ações realizadas fora de fronteiriças na luta contrainsurgente era de domínio de um restrito círculo de oficiais, dada a configuração clandestina e encoberta das mesmas.

O período de maior atividade da conexão repressiva regional foi o biênio 1976-77 e para seu funcionamento eficiente foi essencial a pré-existência de afinidades políticas, econômicas e ideológicas - garantidas pelas diretrizes da DSN - e pela reciprocidade nas ações de colaboração e coordenação. Nessa perspectiva, o Uruguai também foi palco da coordenação repressiva contra cidadãos estrangeiros. De fato, a presença de agentes argentinos com documentação falsa $e$ imunes aos controles internos foi uma constante, como no caso de Aníbal Gordon, que viria a ser o principal responsável por Automotores Orletti e grande colaborador dos comandos uruguaios que agiriam em Buenos Aires. ${ }^{28}$

A centralização das atividades da seção uruguaia da Condor ficou nas mãos do Organismo Coordinador de Operaciones Antisubversivas (OCOA). Chefiado pelo major José Nino Gavazzo, o OCOA teve participação na eliminação de aproximadamente 135 cidadãos uruguaios refugiados na Argentina; Automotores Orletti foi sua principal base de operações. O comando geral da unidade era responsabilidade do diretor do Servicio de Inteligencia y Defensa (SID), general Amauri Prantl enquanto que a parte operativa era dirigida pelo citado Gavazzo. Outros agentes envolvidos foram os militares Manuel Cordero, Enrique Martínez, Jorge Silveira, Gilberto Vázquez, Ernesto Ramas, José Arab, Luiz Mata, Ramón Díaz Olivera, Ernesto Soca e os policiais de inteligência Hugo Campos Hermida, Ricardo Medina e José Sande ${ }^{29}$. Pela contraparte argentina respondia o diretor do Servicio de Inteligencia de Estado (SIDE), general Otto Paladino (quem havia sido um dos fundadores da Triple A) e o também citado Aníbal Gordon, quem antes do golpe chefiava um grupo paramilitar conhecido como La banda de Gordon. ${ }^{30}$ A jurisdição do centro clandestino de detenção era do I Corpo do Exército. Faziam parte da unidade argentina agentes como Honorio Martínez Ruiz, Raul Guglieminetti, Eduardo Ruffo e Miguel Angel Furci, estes dois últimos, sequestradores das crianças Carla Rutila Artés e Mariana Zaffaroni Islas respectivamente.

Duas grandes ondas de seqüestros e desaparições de cidadãos uruguaios aconteceram na capital portenha entre junho e setembro de 1976. Ao redor de 70 pessoas foram sequestradas, a maioria pertencente ao Partido por la Victoria del Pueblo cujas bases foram desarticuladas. Quase todos esses militantes foram levados a Automotores Orletti.

\footnotetext{
${ }^{28}$ No Uruguai Gordon circulava com desenvoltura e documentação que o identificava como oficial da marinha local. SERPAJ, "Uruguay Nunca Más...", p. 337.

${ }^{29}$ REY PIUMA, Daniel. Los crímenes del Río de la Plata. Córdoba: El Cid Editor, 1984, p. 36. Trata-se de detalhada denuncia sobre o funcionamento do aparato repressivo realizada por um agente arrependido. Ver também: TRİAS \& RODRÍGUEZ, "Gerardo Gatti...", p. 304-305.

${ }^{30}$ MARIANO, Nilson C. Operación Cóndor. Terrorismo de Estado en el Cono Sur. Buenos Aires: Lohlé-Lumen, 1998, p. 66.
} SÆCUlUM - REvisTA DE HisTóRIA [39]; João Pessoa, jul./dez. 2018. 


\section{Automotores Orletti: a caverna da Condor}

$\mathrm{Na}$ atualidade, Automotores Orletti integra a rede argentina de Sítios de Memória do Terrorismo de Estado. Durante sua curta existência, o lugar funcionou de forma totalmente clandestina. As denúncias realizadas no exterior por Enrique Rodríguez Larreta ${ }^{31}$ - quem ali fora recluso -, explicitaram sua existência e seu funcionamento, a coordenação e colaboração entre agentes das ditaduras uruguaia $e$ argentina e o papel dos comandos uruguaios do OCOA e da SID. O centro clandestino estava localizado em uma velha casa de dois andares, na Rua Venancio Flores 3519, no bairro Floresta, em Buenos Aires. A sua fachada era a de uma oficina mecânica e havia sido alugada pelo agente da SIDE Eduardo Ruffo com o objetivo de transformar o local em uma base de operações desse serviço de inteligência para efeitos de participação na Operação Condor. Uma pesada cortina de metal servia de portão de entrada para automóveis; detrás do mesmo, havia um espaço de aproximadamente oito metros de largura por trinta de profundidade; no mesmo, os depoimentos dos sobreviventes indicam que havia carros roubados das próprias vítimas e chassis abandonados, objetos diversionistas úteis para mascarar a verdadeira função da aparente pacata oficina mecânica. No fundo desse grande espaço que ocupava toda a planta baixa, havia uma escada de material e degraus de madeira que comunicava com o andar superior, onde se encontravam as salas de tortura.

Orletti funcionou entre maio e novembro de 1976 e dentro da estrutura repressiva da ditadura argentina, era a base de operações dos Grupos de Tarefa (as unidades responsáveis pelos sequestros de suspeitos de subversão) vinculados à SIDE e à Superintendência da Polícia Federal. O local situavase na frente da ferrovia do trem Sarmiento, próximo da Estação Floresta. Tal informação é importante, pois os sobreviventes lembram que ouviam com regularidade, a passagem de trens, dado essencial no momento de tentar localizar esse centro clandestino. Outro sinal apurado, apesar da rigorosa incomunicabilidade imposta e da ausência quase total de percepção sensorial (obstruída pelo uso obrigatório do capuz), foi o som cotidiano de vozes de crianças. Quando da posterior identificação desse local de confinamento, bem depois da sua desativação, verificou-se que o mesmo era vizinho de uma escola com a qual estava geminada.

Entre os agentes que ali atuavam o local era conhecido como El Jardín ou La Cueva de Gordon, alusão a Aníbal Gordon, responsável pelo mesmo. O nome Automotores Orletti é fruto de uma confusão. Em realidade, na frente do prédio, no tempo em que de fato existia uma oficina mecânica, havia uma placa que dizia Automotores Cortell; Cortell era o sobrenome do dono e morador do estabelecimento e do prédio, quem, aliás, o alugara à SIDE. Tudo indica que as pessoas que o identificaram pela primeira vez, ainda durante a ditadura, procurando memorizar algum traço particular do mesmo, teriam lido, apressadamente, Orletti em vez de Cortell; há lembranças de antigos vizinhos que indicam que, efetivamente, a letra $\mathrm{C}$ estava apagada na placa.

A entrada de veículos no recinto ocorria principalmente pela noite, para evitar chamar a atenção da vizinhança. Os sobreviventes apontam em seus depoimentos que quando chegavam os automóveis, depois de realizar algum operativo, era acionado via rádio a palavra-chave Operación Sésamo ou simplesmente Sésamo, alusão ao conto de Ali Baba e os quarenta ladrões - por isso, os repressores se referiam a essa base nomeando-a Caverna ou Cueva. A pesada porta era aberta através de um mecanismo interno. O espaço maior do andar térreo era obstruído aos olhares curiosos de quem caminhasse pela rua por uma cortina de tecido que escondia os detidos encapuzados, amarrados $e$ sentados ou deitados diretamente sobre o cimento frio e sujo de graxa e terra.

Os uruguaios sequestrados em Orletti eram, na grande maioria, vinculados ao PVP. A detenção de quatro militantes na cidade de Colônia, no Uruguai, no mês de março de 1976 marcou o início de uma autêntica débâcle que, além de atingir importantes quadros e infraestrutura da organização em

\footnotetext{
${ }^{31}$ Jornalista uruguaio sequestrado e torturado em Buenos Aires quando procurava informações sobre seu filho desaparecido poucos dias antes, como resultado de uma ação massiva contra cidadãos uruguaios. Posteriormente, junto com outros compatriotas também detidos em Orletti, foi levado clandestinamente ao Uruguai onde, tempo depois, acabou libertado. A partir desse momento iniciou intensa campanha internacional denunciando o sequestro de que tinha sido objeto, a existência de locais clandestinos de detenção na Argentina e no Uruguai, a colaboração repressiva entre as duas ditaduras, a farsa da Operación Invasión e os crimes que vinham cometendo contra perseguidos políticos. Sua extensa e documentada denúncia, feita em Londres, em março de 1977, consta no site http://elinforme.larreta.org/. Acesso em: 24/05/17. 
Montevidéu, teve efeitos imediatos sobre os grupos articulados na capital bonaerense. Como efeito dominó, a cada queda de militantes, apreensão de material e sessão de "interrogatório", se seguiram novas quedas em ritmo alucinante. Os desdobramentos da imposição da ditadura na Argentina sobre o universo exilado intensificou a sensação de colapso das organizações vinculadas. A falta de resistência à ascensão da Junta Militar propiciou que o Estado fosse rapidamente ocupado pelas forças golpistas $e$ seus efeitos nefastos se espalhassem de forma dramática entre os setores de esquerda. Os acontecimentos atropelaram os dirigentes dessas organizações e sua capacidade de gerenciar, em ritmo de urgência, a tomada de decisões táticas e estratégicas; esse foi o caso do PVP, atingido de forma letal, logo após a ruptura democrática.

"Em agosto de 1976 a direção do PVP reconhecia que mais de $50 \%$ dos seus dirigentes havia sido sacrificado". ${ }^{32}$ Uma hipótese levantada para explicar tantas quedas - não só do PVP, mas de todas as organizações, exiladas ou não, perseguidas na Argentina -, e a demora em ordenar a retirada da militância a outros países está vinculada a que, na voragem dos acontecimentos, o cálculo de perdas ( $e$ quedas) foi feito em cima de uma imprecisão central: levar em conta o registro de mortos, mas não o de desaparecidos. Obviamente que, na época, não se conhecia o que significava o desaparecimento forçado e se ignorava o caráter massivo da engenharia de extermínio que estava em andamento; isso não era compreensível nos primeiros meses após o golpe de Estado. As informações que reverberavam na imprensa filtravam a realidade dos sequestros e do não aparecimento de cadáveres (ou pelo menos não no volume real); essa falta de precisão dificultava sobremaneira os cálculos e apreciações dos setores perseguidos. Dentro dessa problemática Inés Izaguirre ${ }^{33}$ aponta que as organizações armadas argentinas estavam militarmente derrotadas no final de 1975. Porém, a consciência subjetiva dos militantes não refletia esse dado concreto. A explicação para essa defasagem na "percepção do desastre" pode ser encontrada na associação de "baixas" (quedas) com "mortos". O número de mortos refletidos na imprensa apontava para um conjunto de quedas que não refletia a realidade dos fatos. Mesmo somando o número de mortos, feridos e presos o dado obtido, mesmo por aproximação, ficava muito distante da sangria que as organizações vinham sofrendo.

$\mathrm{O}$ desconhecimento sobre a concretude do que era um desaparecido e sobre o número dos que estavam em essa situação fazia que a contabilização de baixas ficasse muito aquém da percepção que, sobre dados bem mais objetivos, manejava o comando das Forças Armadas. Estas não só tinham consciência do significado e desdobramentos da lógica sequestro-tortura-execução extrajudicial/desaparecimento dos corpos, como haviam criado uma infraestrutura de "depósitos" clandestinos de inimigos internos sequestrados cujos rastos se perdiam na "noite e nevoeiro" do TDE. Ou seja, retirados dos seus círculos sociais e políticos, os perseguidos ficavam disponíveis para uma maquina de terror que procurava não deixar rastos dos sequestros e negava qualquer evidência do seu envolvimento. Invisíveis aos olhos da população, os centros clandestinos de detenção serviam para realizar o filtro $e$ a triagem de detidos e funcionavam, todavia, como depósitos temporários $e$ chupaderos - locais de execução, desaparecimento de cadáveres. Por conseguinte, nos primeiros meses de 1976 ocorreu uma acentuada subavaliação do tamanho da derrota, destruição e extinção das organizações de esquerda pelo desconhecimento da novidade que implicava o desaparecimento forçado e massivo como política de Estado.

A falta de informação precisa para avaliar o real quadro de forças também atingiu a comunidade exilada no país, em especial a uruguaia, pressionada pela conjuntura regional e pela feroz perseguição política local. Como se não bastasse, a impunidade das unidades condores do país de origem, que sobrevoavam o território argentino - até então associado à certa garantia de acolhimento e proteção -, produzia efeito nefasto. A repressão uruguaia na Argentina tinha um motivo adicional para acuar o PVP. Além de esta organização política ter o perfil de inimigo interno agindo fora do país, se concentrava em uma área contígua à fronteira oriental e muito próxima de Montevidéu, o que era interpretado pelo governo Bordaberry como fato muito perigoso. Mas havia outro móvel que estimulava sobremaneira a captura de dirigentes e militantes. Ocorre que diante da necessidade de

\footnotetext{
32 TRÍAS \& RODRÍGUEZ, “Gerardo Gatti...”, p. 304.

${ }^{33}$ IZAGUIRRE, Inés. Lucha de clases, guerra civil y genocidio en la Argentina 1973-1983: antecedentes, desarrollo, complicidades. Buenos Aires: Eudeba, 2009, p. 102.
} 
garantir a sustentação material dos seus quadros - muitos em condições materiais paupérrimas - $e$ frente à necessidade de obtenção de documentos e montagem de uma infraestrutura de aparelhos $e$ comércios de fachada, o PVP e as organizações que o criaram, haviam realizado na Argentina sequestros de empresários visando exigir resgate para obtenção de fundos com os quais se financiava a infraestrutura e as demandas mais urgentes dos militantes da organização. No Uruguai, as unidades especializadas no combate ao PVP haviam descoberto, mediante intensa utilização da tortura, que um desses sequestros ${ }^{34}$ rendera uma soma de dez milhões de dólares, montante que estaria nas mãos de quadros dirigentes que viviam na Argentina. Este dado provocou alvoroço e maior sanha nos comandos repressivos que agiam em Buenos Aires. Orletti foi o local onde se tentou fechar o cerco procurando apurar informações que pudessem levar a esse dinheiro. Finalmente, após dezenas de detenções, da inédita chantagem com a vida de dois importantes dirigentes (Gerardo Gatti e León Duarte, sequestrados, barbaramente torturados e finalmente desaparecidos), e com novos operativos "rastilhando" os imóveis ocupados pelos militantes do PVP, boa parte daquele dinheiro caiu nas mãos da repressão. 35

Dentro do esquema uruguaio de utilização de Automotores Orletti como base de operações para as suas atividades repressivas em Buenos Aires pode-se inferir que havia duas grandes motivações. A primeira, o combate e a destruição de um inimigo interno pontual, o PVP e sua rede de contatos; a segunda, a cobiça alimentada pelo desejo de apropriação do dinheiro do inimigo, não só como forma de enfraquecê-lo, mas também por motivações de ordem pessoal, ou seja, a possibilidade de locupletamento assentado na impunidade e no encobrimento dessas ações clandestinas.

Por Automotores Orletti passaram mais de trezentas pessoas, a maioria acabou desaparecida $e$ muitos cadáveres, até hoje, não foram encontrados ou identificados. As vítimas sofreram nesse lugar uma brutal condição de desumanidade e desinformação. Ali aconteceram maus-tratos, tortura, violações, extorsões, roubos e assassinatos; o desaparecimento dos seus cadáveres ocorreu em outros locais. Sabe-se, atualmente, que além de cidadãos argentinos e uruguaios também passaram por Orletti sequestrados de origem chilena, peruana, boliviana e cubana. Ainda, diversas crianças que haviam sido sequestradas com os pais, ali estiveram; a maioria acabou tendo a identidade apropriada $e$ foi adotada ou criada por famílias vinculadas direta ou indiretamente à repressão; entre os casos mais emblemáticos merecem menção os irmãos Julien Grisonas, Mariana Zaffaroni e Macarena Gelman ${ }^{36}$. Cabe acrescentar, por fim, que dessa base partiram, em maio de 1976, os responsáveis pelo sequestro e execução do ex-presidente da Câmara de Deputados do Uruguai e representante do Partido Blanco, Héctor Gutiérrez Ruiz, e do senador da Frente Ampla, Zelmar Michelini, provavelmente o caso mais simbólico de todos os crimes cometidos pela ditadura uruguaia contra cidadãos do seu país, dentro ou fora das próprias fronteiras nacionais. ${ }^{37}$

\footnotetext{
${ }^{34}$ Em março de 1974 a OPR-33, uma das organizações que depois se fusionariam no PVP, havia sequestrado o empresário holandês Federico Hart, vinculado ao setor lanífero e com histórico de negócios turvos. Dez milhões de dólares foram obtidos no pedido de resgate. Há indícios de que a repressão uruguaia ficou com aproximadamente sete milhões de dólares enquanto que a banda de Gordon e a Polícia Federal argentina ficaram com algumas centenas de milhares de dólares. Como exista um acordo de divisão do botim do PVP em três partes iguais, considera-se que os agentes uruguaios não informaram aos colegas argentinos do montante que estava sendo procurado.

${ }^{35}$ Para maiores informações sobre a chantagem contra o PVP ver: RODRÍGUEZ, Roger. Los crímenes de "Automotores Orletti”. Disponível em: http://elmuertoquehabla.blogspot.com/2007/03/los-crmenes-de-orletti.html. Acesso em: 25 jul. 2018.

${ }^{36}$ UDELAR. Investigación Histórica sobre la Dictadura y el Terrorismo de Estado en el Uruguay. (1973-1985). T II. Montevideo, 2008.

${ }^{37}$ A execução dos dois parlamentares uruguaios junto com outros dois exilados é lembrado no dia 20 de maio de cada ano, quando ocorre a impactante Marcha del Silencio, data maior de homenagem aos mortos e desaparecidos políticos vítimas do Terrorismo de Estado uruguaio. 


\section{O destino dos uruguaios de Orletti}

Em novembro de 1976, José Ramón Morales e Graciela Videillac, cidadãos argentinos detidos em Orletti, conseguiram burlar a guarda e fugir, fato que obrigou os responsáveis pelo centro a desativá-lo imediatamente para preservar o caráter clandestino da luta contra a subversão antes que ocorresse o vazamento à imprensa e à opinião pública internacional. De fato, pouco tempo depois, o casal conseguiu chegar ao México, onde denunciou tudo o que sabia. Enquanto isso, os prisioneiros de Automotores Orletti eram "trasladados" (eufemismo dado aos desaparecidos) ou levados a outros centros clandestinos de detenção. No caso da coordenação repressiva platina, com a desativação de Orletti, o Pozo de Banfield e o Pozo de Quilmes adquiriram maior relevância.

Dezenas foram os perseguidos políticos uruguaios que estiveram sequestrados em Orletti. Muitos acabaram desaparecidos. Outros tantos foram entregues ao governo do Uruguai; vários destes foram usados pela ditadura para a montagem de uma peça de inteligência e propaganda baseada em uma farsa grotesca que afirmava que haviam sido presos ao retornar ao país, ilegalmente, com o objetivo de retomar a luta armada (a pseudo-ação foi denominada Operación Invasión). ${ }^{38}$ Efetivamente, no dia 24 de julho de 1976, 24 cidadãos uruguaios detidos em Orletti foram levados clandestinamente a Montevidéu em um voo especial da Força Aérea Uruguaia. Tal deslocamento ficou conhecido como "Primeiro voo". Esta ação consistiu em uma ação de inteligência destinada a alertar à opinião pública internacional de que o perigo subversivo persistia. No fundo, era um artifício que visava reverter o cumprimento de uma promessa de campanha do então candidato às eleições presidenciais dos EUA, James Carter, quem anunciava que, em caso de vitória, suspenderia toda ajuda econômica às ditaduras do Cone Sul em função das volumosas denúncias de violação de direitos humanos. De fato, tal ameaça se concretizou com a vitória do candidato democrata em detrimento da candidatura republicana fiadora da manutenção dos esquemas de apoio irrestrito aos regimes de exceção.

A pantomima da Operación Invasión concluiu com a "detenção" dos envolvidos, os quais, esposados, foram fotografados posando junto a um importante arsenal que, em tese, seria utilizado para as ações que "pretendiam" desencadear. A imprensa repercutiu os comunicados oficiais das Forças Armadas sobre a suposta invasão de subversivos que pretendia retomar a luta armada. A população ficou chocada com o teor das "notícias" que indicavam que um grupo fortemente armado havia sido detido pouco antes de efetivar ações de impacto.

Após o "Primeiro voo" houve uma segunda onda de capturas de integrantes do PVP em Buenos Aires, entre setembro e outubro de 1976, também centralizada em Orletti. No 5 de outubro, no bojo da desativação do centro de detenção pelos motivos já expostos, um "Segundo voo" clandestino da Força Aérea Uruguaia transportou a Montevidéu 22 desses detidos. ${ }^{39}$ Este contingente estava destinado a fazer parte da citada Operación Invasión. Segundo as informações transmitidas à imprensa uruguaia, o número de detidos na tal operação correspondia à soma de pessoas transportadas a Montevidéu nos dois voos citados. Porém, somente os nomes e as fotos daqueles que haviam estado no "Primeiro voo" vieram a público. As informações sobre os demais nunca foram divulgadas. Os transportados no "Primeiro voo", dos quais seu escondeu da opinião pública sua captura em Buenos Aires, a estadia em Orletti e a posterior remoção a Montevidéu, sofreram condenação e foram encaminhados à prisão até o final da ditadura. Quanto aos demais, nada veio a público. Ou seja, para todos os efeitos, permaneciam na Argentina em situação desconhecida para familiares, amigos $e$ companheiros. O jornalista Roger Rodríguez investigou o caso e levantou indícios, a partir de informações fornecidas por uma importante fonte vinculada à repressão argentina, de que o segundo grupo de uruguaios que desapareceu em Automotores Orletti (cerca de 27 indivíduos), foi entregue às Forças Armadas uruguaias. Em Montevidéu, o grupo foi encaminhado ao centro de tortura conhecido

\footnotetext{
${ }^{38} \mathrm{O}$ major Gavazzo voltou de Montevidéu com a notícia de que mais de 20 uruguaios sequestrados seriam repatriados (para utilizá-los na planejada "invasão"), houve dura discussão com os oficiais argentinos que atuavam em Orletti. Os argentinos exigiam que se respeitasse um acordo anterior entre ambas as partes de que não haveria sobreviventes. Consideravam a atitude do governo uruguaio um grave e ameaçador precedente que poderia constituir-se em futuro risco para a segurança (impunidade e imunidade) dos operativos. AMORÍN, Carlos. Sara - Buscando a Simón. Montevideo: Ediciones de Brecha, 1996, p. 44.

${ }^{39}$ A existência deste vôo somente foi reconhecida em 2005 por autoridades militares uruguaias.
} 
como 300 Carlos, anexo ao quartel do Batalhão 13; ali permaneceu durante quase um mês. Posteriormente, todos os integrantes foram executados e seus corpos desaparecidos. Durante anos se silenciou sobre esse segundo voo e se manteve a versão oficial de que no Uruguai não haviam ocorrido desaparecimentos. Até então se considerava, apesar da desconfiança, que, de fato, os cidadãos uruguaios desaparecidos tinham sofrido esse destino fora de fronteiras, particularmente na Argentina. A divulgação dessa versão oficial foi veementemente rejeitada pela fonte argentina de Rodríguez que, com o tempo, contribuiu para o esclarecimento de outros casos envolvendo cidadãos uruguaios sequestrados naquele país. Com indignação, a fonte pronunciou que:

De Uruguay a los argentinos nos han cobrado todo y mucho ha salido a luz. Pero que no nos adjudiquen esas desapariciones. A los que no murieron en Orletti nosotros los devolvimos. No sabíamos que los del primer viaje estaban vivos, así que cuando cerraba Orletti se planificó otro viaje grande en el que se incluyó a todos los que quedaban, incluso cinco argentinos. No participé en la entrega, pero creo que a esos últimos tienen que buscarlos en Uruguay. ${ }^{40}$

Em outra matéria, o mesmo Roger Rodríguez ${ }^{41}$ aprofundou a informação recolhida e levantou importantes hipóteses sobre a responsabilidade da ditadura uruguaia sobre aqueles acontecimentos. Segundo ele, o resto dos uruguaios de Orletti, contrariamente ao que se divulgou ou especulou durante muitos anos, não recebeu disposición final (outro eufemismo de desaparecidos) na Argentina, ou seja, não foram executados nem tiveram seus corpos desaparecidos naquele país, o que ajuda a explicar por que as equipes de antropologia forense do país vizinho nunca identificaram os restos de nenhum daqueles cidadãos uruguaios. Por outro lado, dificilmente teriam sido vítimas da metodologia dos "voos da morte" (jogar as vítimas nas águas do Río de la Plata ou no Oceano Atlântico), pois o Uruguai não possuía, na época em que foram perpetrados esses crimes, aviões tipo Hércules, que permitiam lançar pessoas em pleno voo (como fez a repressão argentina). Finalmente, Rodríguez ressalta que, a opção restante, é a de que aquelas pessoas foram levadas ao Uruguai e ali receberam a disposición final e, provavelmente, foram enterrados em quartéis do país. Dados atuais confirmam a existência de cemitérios clandestinos em um par de quartéis, tendo sido encontrados restos humanos; porém, até agora, são casos excepcionais. De qualquer forma, há um entendimento de que, em determinado momento, a ditadura deu ordem para remover a terra, extrair os restos humanos enterrados e depositá-los em outro local, o que teria sido feito como ação preventiva para dificultar hipotéticas tentativas futuras de procura de vítimas em áreas militares (este ato diversionista foi denominado Operación Zanahoria).

Em relação a essas informações outro jornalista uruguaio, Samuel Blixen, ${ }^{42}$ acrescenta que, caso se confirme que aquelas pessoas sequestradas na Argentina tenham sido entregues à ditadura uruguaia, caem por terra, definitivamente, as argumentações sustentadas durante décadas pelas Forças Armadas após a revelação da farsa da Operación Invasión. Apesar do revés sofrido com o desmoronamento da falsa fachada, haviam aproveitado a divulgação dos nomes dos repatriados de Orletti do "Primeiro voo" como "prova" de que os comandos que agiam em Buenos Aires, em realidade, haviam "resgatado" da morte os prisioneiros uruguaios que estavam nas mãos dos "assassinos argentinos". Simultaneamente, com essa afirmação se sugeria que a sorte dos demais uruguaios de Orletti correu por conta dos militares do país vizinho, o que reforçava a "mentira" oficial de que no Uruguai não havia ocorrido execução sistemática de presos.

As evidências posteriores corroboraram a existência dessa última entrega de presos de Orletti à ditadura uruguaia, derrubando a hipocrisia da versão governamental e desvelando, mesmo que em parte, a essência do "pacto de silêncio" entre os militares envolvidos na coordenação repressiva da Operação Condor, sobre a qual sempre afirmaram desconhecer qualquer informação e negaram tudo o que tivesse relação com a sua participação. Além disso, fragilizou o argumento das Forças Armadas de que "cumpriram seu dever" salvando da morte todos os subversivos que fora possível, e que a

\footnotetext{
${ }^{40}$ La República, 17 oct. 2002 , p. 2 e 3.

${ }^{41}$ Brecha, n 851, 09 jun. 2002.

${ }^{42}$ Rebelión, 03 febr. 2002. 
morte dos demais detidos foi exclusivamente de responsabilidade do governo Videla. Novas informações levantadas pela imprensa, nos primeiros meses de 2005, confirmaram a existência de outras entregas de cidadãos uruguaios sequestrados em Buenos Aires, como ocorrera com os envolvidos na Operación Invasión. Contudo, diferentemente deste grupo, o que foi entregue posteriormente, continua desaparecido, o que significa que, dadas as evidências, as pessoas que o integravam foram executados no Uruguai e seus corpos foram desaparecidos. ${ }^{43} \mathrm{Ou}$ seja, é a confirmação de que além de participar ativamente na conexão repressiva regional, a ditadura uruguaia repatriou clandestinamente compatriotas sequestrados no exterior, os executou $e$ desapareceu seus corpos dentro do território nacional, insistindo no desconhecimento dos fatos e negando qualquer responsabilidade em relação aos mesmos. O mais grave é que, para isso, contou com a cumplicidade dos posteriores governos democráticos administrados pelos partidos Colorado $e$ Blanco.

\section{Reflexões finais}

Os acontecimentos relacionados com os cidadãos uruguaios que foram levados ao centro clandestino de detenção argentino Automotores Orletti são a maior demonstração da conexão repressiva que dinamizou o combate contra todos aqueles que no Cone Sul foram identificados como inimigos internos. A presença de comandos militares uruguaios na capital portenha sem nenhum tipo de dificuldade operativa exemplifica a armadilha que virou a região para quem teve que atravessar fronteiras terrestres ou fluviais e entrar em território vizinho. A experiência sofrida pelo PVP confirma a tese de Molina Theissen de que parte das Forças Armadas latino-americanas foi transformada - através da DSN e da instrução e do treinamento adquiridos nas escolas e academias militares estadunidenses , em forças de ocupação interna, ou seja, de controle das suas próprias sociedades. ${ }^{44} \mathrm{~A}$ perseguição $e$ eliminação dos inimigos internos que se encontravam no exterior, corrobora essa tese; tais ações foram realizadas dentro do marco comum de entendimento de que no combate àqueles, as fronteiras nacionais não deviam ser empecilhos, já que a sobrevivência da subversão afetava a segurança regional como um todo. Nesse sentido, o território dos países do Cone Sul, dentro do acordo chancelado no marco da colaboração repressiva, era avaliado como sendo uma extensão do próprio território nacional. De certa forma, apesar de clandestina, a base de Orletti, fruto de acordos encobertos, tinha para os comandos uruguaios e dos demais países envolvidos, a mesma importância e estatuto que, em tese, detinha qualquer embaixada ou consulado, ou seja, constituía uma extensão do próprio território nacional com direito à soberania, imunidade e impunidade dentro do território de outro país.

Comparativamente, de todos os países envolvidos na conexão repressiva regional, o Uruguai foi o país que teve, proporcionalmente, o maior número de cidadãos desaparecidos e/ou mortos no exterior (incluindo as crianças sequestradas e apropriadas), maior até que o número de vítimas produzidas no seu próprio território, o que confere ao seu TDE uma impactante singularidade. Isso leva a avaliar que a participação uruguaia na coordenação repressiva internacional não se restringiu a fatos isolados contra alvos selecionados; em realidade, foi uma verdadeira caçada humana, uma operação sistemática de grandes proporções, produzindo e espalhando pânico e terror entre a numerosa comunidade exilada ou afixada principalmente na Argentina. Esse dado calibra de forma mais precisa o grau de integração entre os comandos uruguaios que atuaram naquele país e as unidades militares argentinas. A urbe portenha virou uma espécie de prolongação do espaço oriental para a atuação do braço repressivo uruguaio, como se fosse mais uma "zona interna" para a aplicação das suas ações contrainsurgentes; isso ocorreu contando com o beneplácito e a colaboração da ditadura argentina, $e$ quando foi necessário houve reciprocidade rioplatense de favores.

Pode-se concluir que Automotores Orletti foi o maior emblema da coordenação repressiva regional,

\footnotetext{
${ }^{43}$ Ver: SILVA, Alberto. Julio Abreu sobreviviente del vuelo cero. Montevideo: Editorial Primero de Mayo, 2013; RICO, Álvaro (Coord.). Investigación Histórica sobre Detenidos Desaparecidos. T I y II. Montevideo: IMPO, 2007.

${ }^{44}$ MOLINA THEISSEN, A. L. La desaparición forzada de personas en América Latina. KO'AGA ROÑE’ETA, Série VII, 1998.

p. 7. Disponível em: http://www.derechos.org/koaga/vii/molina.html. Acesso em: 06 jul. 2018.
} 
independente do seu curto período de funcionamento. Os cidadãos latino-americanos que ali foram levados sentiram a onipotência dos sequestradores - donos da vida e da morte -, no horror da tortura aplicada em carne própria e nos gritos de companheiros e desconhecidos. Nesse espaço e nesse tempo congelado, de incerteza, medo e maus tratos, os sequestrados vivenciaram uma experiência marcada por uma condição de fragilidade total, de brutalidade e chantagens, à espera de um desfecho que, salvo exceções ou por cálculo ou capricho dos captores, significou uma morte diluída em desaparecimentos fantasmagóricos e ausência de restos insepultos, o que se projetou no tempo como uma continuidade do horror e do trauma sobre seus familiares e amigos.

Em síntese, Orletti foi a síntese da sobreposição organizada das políticas internas de Terrorismo de Estado extrapoladas para além fronteiras e sinônimo de colaboração repressiva ilimitada. Orletti foi o epicentro do voo do condor; tortura, rapina, apropriação de crianças e assassinatos foram o seu produto como efeito colateral desejado na luta contra um inimigo interno que, segundo a prédica oficial, ameaçava destruir a civilização ocidental. Por fim, Orletti foi o símbolo do congraçamento das Ditaduras de Segurança Nacional, dos seus associados e dos seus interesses materiais. 


\section{RESUMO}

O artigo situa a problemática da perseguição contra a oposição política no Cone Sul, no contexto das ditaduras de segurança nacional. Particularmente, analisa a presença de exilados uruguaios em Buenos Aires, especialmente da militância do Partido por la Victoria del Pueblo $e$ as represálias sofridas, a partir de março de 1976, através de ações repressivas vinculadas à Operação Condor. Automotores Orletti foi a principal base de operações da coordenação repressiva regional, servindo como local de atuação dos comandos uruguaios e centro clandestino de detenção e seqüestro de centenas de perseguidos políticos latinoamericanos. Nesse sentido, apresentam-se características das ações contra-insurgentes contra os núcleos de exilados, informações sobre o papel de Automotores Orletti no contexto da infra-estrutura repressiva da Argentina, bem como do seu funcionamento cotidiano, $e$ a atuação dos comandos que ali atuavam. Por fim, analisa-se o que ocorreu com os detidos uruguaios quando se procede a clausura desse recinto clandestino.

Palavras chave: Automotores Orletti; Operação Condor; Ditaduras de segurança nacional.

\begin{abstract}
This paper addresses the problem of persecution against political opposition in the Southern Cone, in the context of national security dictatorships. In particular, it analyzes the presence of Uruguayan exiles in Buenos Aires, especially the militancy of the Party for The People's Victory and the reprisals they suffered, since March 1976, through repressive actions linked to Operation Condor. Orletti Automotors was the main base of operations of the regional repressive coordination, serving as a place of action for Uruguayan commandos and a clandestine center for the detention and abduction of hundreds of political persecuted Latin-Americans. In this sense, it will be presented the characteristics of the counterinsurgent actions against the exile nuclei, information about the role of Ortetti Automotors in the context of the repressive infrastructure of Argentina, as well as their daily functioning, and the performance of the commandos who worked there. Finally, it is analyzed what happened with the Uruguayan detainees when the closure of this clandestine enclosure happened.
\end{abstract}

Keywords: Orletti Automotors; Operation Condor; National security dictatorships

Artigo recebido em 15 ago. 2018.

Aprovado em 05 set. 2018. 
